\title{
Gait Rehabilitation Device in Central Nervous System Disease: A Review
}

\author{
Kazuya Kubo, ${ }^{1}$ Takanori Miyoshi, ${ }^{1}$ Akira Kanai, ${ }^{2}$ and Kazuhiko Terashima ${ }^{1}$ \\ ${ }^{1}$ Toyohashi University of Technology, Hibarigaoka 1-1, Tempaku-Cho, Toyohashi, Aichi 441-8580, Japan \\ ${ }^{2}$ Department of Physical Therapy, Toyohashi Sozo University School of Health Sciences, 20-1 Matsushita, Ushikawa-Cho, \\ Toyohashi, Aichi 440-8511, Japan \\ Correspondence should be addressed to Kazuya Kubo, kubo@syscon.me.tut.ac.jp \\ Received 1 June 2011; Accepted 8 August 2011 \\ Academic Editor: Haruhisa Kawasaki
}

Copyright () 2011 Kazuya Kubo et al. This is an open access article distributed under the Creative Commons Attribution License, which permits unrestricted use, distribution, and reproduction in any medium, provided the original work is properly cited.

Central nervous system diseases cause the gait disorder. Early rehabilitation of a patient with central nervous system disease is shown to be benefit. However, early gait training is difficult because of muscular weakness and those elderly patients who lose of leg muscular power. In the patient's walking training, therapists assist the movement of patient's lower limbs and control the movement of patient's lower limbs. However the assistance for the movement of the lower limbs is a serious hard labor for therapists. Therefore, research into and development of various gait rehabilitation devices is currently underway to identify methods to alleviate the physical burden on therapists. In this paper, we introduced the about gait rehabilitation devices in central nervous system disease.

\section{Introduction}

Walking is one of the most basic forms of locomotion. Factors obstructing the ability to walk include aging, orthopedic disease (e.g., fracture), and central nervous system (CNS) disease (e.g., cerebrovascular disease (CVD) and spinal cord injury (SCI)). Decreased power of the lower limb muscles, decreased range of motion, and pain can all contribute to gait disorder due to aging and orthopedic disease. Causes of gait disorder with CNS disease likewise include decreased power of the lower limb muscles and decreased range of motion, along with effects on the locomotion center. Rehabilitation is achieved as shown in Figure 1. The method of learning gait involves passive gait exercise by two therapists. To teach a patient how to walk again, therapists must guide the leg movements of the patient, and this task usually requires one therapist for each leg [1-4]. Hospital-based rehabilitation is generally carried out 4-5 times a week for about $10-20$ min per session and is very physically taxing, so prolonged sessions often prove to be difficult. Research into and development of various gait rehabilitation orthoses is currently underway to identify methods to alleviate the physical burden on therapists. This paper outlines SCI and
CVD as two of the major causes of gait disturbance and introduces gait rehabilitation for CNS disorders as well as the gait rehabilitation orthoses currently being studied. Muscle strengthening is not addressed in this study, as that issue encompasses areas other than CNS disorders. Moreover, functional electrical stimulation (FES) can be used as a method of learning gait. However, the purpose of FES is to achieve motion assistance and to facilitate learning gait. As distinguishing these two functions is difficult, this method was excluded from the present paper.

\section{Spinal Cord Injuries}

Spinal cord injuries (SCIs) occur when the spinal cord is damaged by trauma to the vertebral column. Similar disabilities can also occur due to internal factors such as spinal cord tumors and herniation. Unlike peripheral nerves, the CNS including the spinal cord is largely unable to repair or regenerate itself after injury. Major causes of CNS injury include motor vehicle and sporting accidents. SCIs are classified as "complete" and "incomplete," with the former referring to transection of the spinal cord resulting in total 


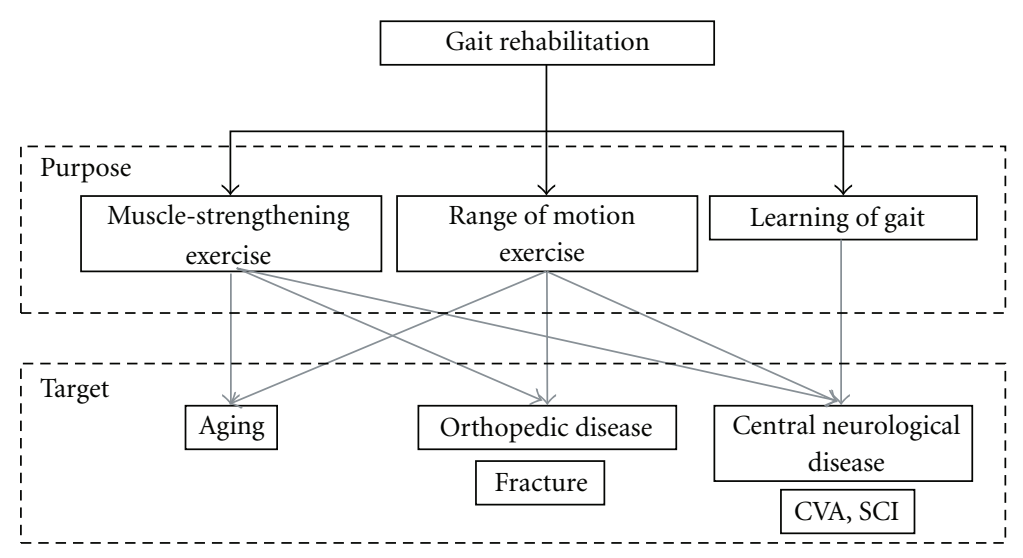

Figure 1: Purpose and target of gait rehabilitation.

interruption of neurotransmission function, and the latter implying partial injury or compression of the spinal cord with only partial loss of function. In complete SCI, control of the area below the injury by the upper CNS is lost along with motor function as signals from the brain fail to reach the injured region. Sensory perception is also lost due to the interruption of sensory pathways carrying information back to the upper CNS. The human vertebral column is divisible into the cervical vertebrae (C1-7), thoracic vertebrae (Th112), lumbar vertebrae (L1-5), sacral vertebrae (S1-5), and coccygeal vertebrae (coccyx). The higher an injury is located on the spinal column, the greater the associated area of paralysis. Complete lower thoracic spinal injuries cause paraplegia, while complete upper thoracic spinal injuries cause quadriplegia and respiratory paralysis. A damaged spinal cord does not recover, so the paralyzed area does not change over time. Rehabilitation therefore targets the area above the injury instead of the paralyzed area below. However, prolonged recumbency causes muscle weakness, so it is preferable to commence the rehabilitation program as soon as possible after sustaining the injury. Although lower thoracic spinal injuries cause paraplegia, central pattern generators (CPGs) present in the spinal cord below the injured area are capable of moving the legs even when motor outputs from the brain do not reach the legs. Accordingly, some gait rehabilitation programs seek to reteach motor activities to CPGs in conjunction with trunk- and armmuscle strengthening and wheelchair training. Patients with upper thoracic spinal injuries involving paralysis of the legs and trunk, but not affecting movement of the arms, often undergo rehabilitation focusing on arm-muscle strengthening and wheelchair training. Gait rehabilitation is performed to prevent orthostatic hypotension and increase physical strength. Some movements of vertebrate animals are thought to be controlled by the neural networks in the spine known as CPGs. These include periodic motions such as walking or swimming. Graham Brown [5] conducted research on CPGs in which decerebrate cats exhibited natural gait when placed in a harness suspended over a moving treadmill and even ambulated when electric stimulus was applied to the area of the brain known as the mesencephalic locomotor region (MLR), leading to the hypothesis that CPGs are present as gait pattern-forming areas in the spine and that walking is the result of interactions between the mesencephalon and the spinal cord. A study verifying the presence of CPGs in swimming was carried out on lamprey eels as primitive vertebrates $[6,7]$, followed by an experiment eliciting treadmill locomotion in monkeys [8]. Research on CPGs in humans [9-12] is also being undertaken in an attempt to achieve ambulation in patients with upper SCIs. Elicitation of ambulatory patterns has been identified as likely to occur with slow gait speed and small load or normal gait speed and large load [13, 14]. Afferent stimuli from proprioceptive sensory organs such as muscle and neurotendinous spindles in the leg muscle groups induce ambulatory patterns via CPGs. Electrical output from CPGs is enhanced by repetitive gait rehabilitation and reduced by the lack of such training $[15,16]$.

\section{Cerebrovascular Disease}

CVD occurs when an anomaly in the intracranial blood vessels nourishing the brain triggers a hemorrhage that eventually damages the brain tissue due to inflammation/ displacement or ischemia. CVD is generally classified into cerebral infarction, cerebral hemorrhage, or subarachnoid hemorrhage according to the form of injury. Cerebral infarction occurs when the supply of blood to the brain is interrupted due to stenosis or occlusion of cerebral arteries as a result of events such as thrombosis. Cerebral hemorrhage refers to the formation of a mass known as an intracerebral hematoma caused by the rupture and subsequent hemorrhaging of brain capillaries. Subarachnoid hemorrhage is a condition in which an aneurysm formed in the subarachnoid space ruptures and the subsequent bleeding places pressure on the brain. Symptoms vary according to the site of the damage, with injuries to the left hemisphere of the brain generally associated with language disorders and injuries in the right hemisphere causing unilateral spatial neglect (USN). However, a common symptom is motor/sensory paralysis on the side contralateral to the injury. Like SCI, 
functions in areas that are damaged by CVD do not recover, but are instead taken over by peripheral and other areas of the body and resumed by reconfiguration of neural networks [17-19]. Beginning rehabilitation as soon as possible after sustaining the injury is recommended to prevent the onset of disuse syndrome. CVD rehabilitation focuses on strengthening the muscles on the unaffected side as well as performing repetitive motor training on the paralyzed side to reteach motor activities to the brain. Rehabilitation programs are designed according to the symptoms of the patient, such as higher brain dysfunction. CVD patients with USN, for example, may undergo symmetrical gait rehabilitation using a mirror.

\section{Gait Rehabilitation in CNS Disease}

Gait rehabilitation is implemented in a variety of ways, according to the condition of the patient. Some examples include the use of walking sticks, lower limb orthoses, parallel bars, walking frames, and treadmills. Aims of rehabilitation include teaching gait action, strengthening muscles, and building endurance. When teaching gait action, the therapist usually holds on to the legs and waist of the patient and provides guidance. This approach may involve the use of a treadmill and suspension device known as a bodyweight support (BWS) system to prevent the patient from falling and to enable the therapist to hold the patient more easily. BWS systems may employ springs, weights, or winches and can be used to preclude the onset of disuse syndrome by enabling gait rehabilitation in patients who cannot assume a standing posture while preventing them from falling [20-24]. Gait retraining targets reticulospinal tract CPGs [25] in SCI patients, and healthy areas of the cerebrum in CVD patients. Input stimuli for the purpose of retraining consist of changes in muscle length detected by muscle spindles and changes in muscle strength detected by neurotendinous spindle. Moving the legs during gait rehabilitation while applying a load is believed to produce input to the CNS regarding changes in muscle length and muscle strength, whereas moving the legs without application of a load only generates inputs for changes in muscle length. Research is therefore being undertaken into ways of automatically controlling load and leg joint movements in order to send stimuli to the CNS during gait rehabilitation in a safe and suitable manner. Gait rehabilitation immediately after injury places a considerable burden on the therapist, making extended sessions difficult. Furthermore, therapist instruction is lacking in terms of reproducibility and is therefore considered unsuitable for certain gait patterns. Accordingly, the following gait rehabilitation devices are being researched and developed to mitigate the physical burden on therapists, enable extended rehabilitation sessions, and provide appropriate stimuli to the CNS. These devices can be broadly classified into four types: those with functions of supporting the body and guiding the legs (lifting device with lower limb orthosis); those with a function of supporting the body only (lifting device); those with a function of guiding the legs only (lower limb orthosis);

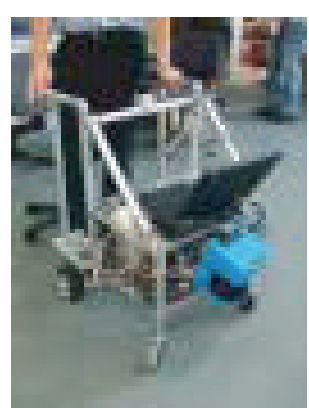

Walker [27]

(a)

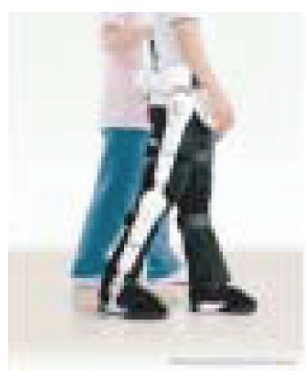

Lower limb orthosis [61]

(c)

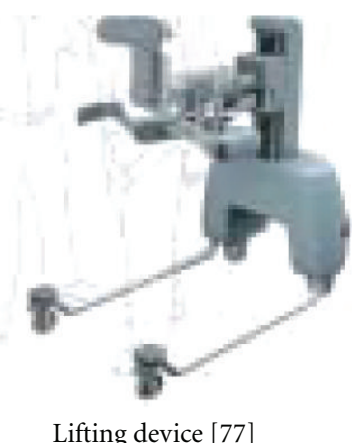

(b)

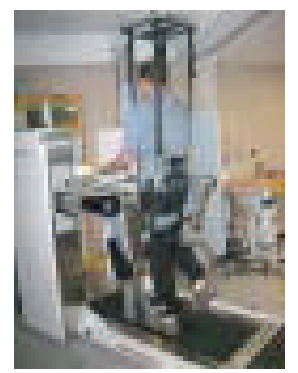

Lifting device with

lower limb orthosis [95]

(d)
Figure 2: Type of gait rehabilitation.

those resembling wheeled walkers or rollators (Walker) as shown in Tables 1 and 2 and Figure 2. The rehabilitation orthoses discussed in this paper are tabulated according to the target user, description of conducted experiments, and system configuration. Rollator-style devices [26-29] are used by individuals with muscle weakness as well as CNS disorder patients and are utilized in daily living as well as in rehabilitation. This broad range of users and applications makes comparison difficult, so these devices have been excluded from the scope of this paper. And FES (Functional Electrical Stimulation) is researched as a gait ability acquisition method [30-33]. In FES, there are two purposes of assistance and rehabilitation of gait. Because these distinctions are difficult, we exclude it in this paper.

\section{Gait Rehabilitation Device}

In a study by Hesse et al. [34] on the feasibility of restoring gait function in CNS disorder patients through repetitive training, comparison of walking cycle and electromyographic (EMG) signals in hemiparetic patients who underwent gait rehabilitation using a BWS system and treadmill or bed-based gait rehabilitation revealed that cyclical walking patterns were induced in patients using the BWS system and treadmill rehabilitation. Hesse et al. also conducted a study in which cerebral palsy patients underwent regular ambulatory rehabilitation using a BWS system and treadmill for 3 months, revealing that gross motor function measure (GMFM) and functional ambulatory category (FAC) scores 
TABLe 1: Reference about gait rehabilitation device number 1.

\begin{tabular}{|c|c|c|c|c|c|c|}
\hline Type & Device name & Target & Rehabilitation method & Subject & Evaluation item & Reference \\
\hline \multirow{13}{*}{$\begin{array}{l}\text { Lower limb } \\
\text { orthosis }\end{array}$} & HAL & Other & Active gait & - & & {$[61]$} \\
\hline & \multirow{3}{*}{ GBO } & \multirow{3}{*}{ CVD } & \multirow{3}{*}{ Active gait } & - & & {$[62]$} \\
\hline & & & & $\begin{array}{l}\text { Healthy } \\
\text { CVD }\end{array}$ & $\begin{array}{l}\text { Knee and hip angle } \\
\text { Knee and hip torque } \\
\text { EMG of lower limbs } \\
\text { Foot trajectory }\end{array}$ & {$[63]$} \\
\hline & & & & $\begin{array}{l}\text { Healthy } \\
\text { CVD }\end{array}$ & Knee and hip angle & {$[64]$} \\
\hline & \multirow{3}{*}{ ALEX } & \multirow{3}{*}{ SCI, CVD } & \multirow{3}{*}{ Passive gait } & Healthy & Foot trajectory & {$[65]$} \\
\hline & & & & CVD & $\begin{array}{l}\text { Knee and hip angle } \\
\text { foot trajectory }\end{array}$ & {$[66]$} \\
\hline & & & & Healthy & Step height & [49] \\
\hline & \multirow[t]{4}{*}{ LOPES } & \multirow[t]{4}{*}{ SCI, CVD } & \multirow[t]{4}{*}{$\begin{array}{l}\text { Passive gait } \\
\text { Active gait }\end{array}$} & Healthy & $\begin{array}{l}\text { Knee and hip angle } \\
\text { Step height }\end{array}$ & {$[50]$} \\
\hline & & & & Healthy & $\begin{array}{l}\text { Knee and hip angle } \\
\text { EMG of lower limbs }\end{array}$ & {$[51]$} \\
\hline & & & & Healthy & $\begin{array}{l}\text { Knee and hip angle } \\
\text { EMG of lower limbs }\end{array}$ & {$[52]$} \\
\hline & & & & - & & {$[67]$} \\
\hline & \multirow[t]{2}{*}{ Nango's research } & & Passive gait & - & & {$[68]$} \\
\hline & & & & - & & [69] \\
\hline \multirow{18}{*}{ Lifting device } & WARD & CVD & Active gait & Healthy & Gait velocity, stride & {$[70]$} \\
\hline & RGR Trainer & CVD & Active gait & Healthy & Pelvic obliquity & {$[57]$} \\
\hline & STRING-MAN & CVD & Active gait & Healthy & ZMP position & {$[71]$} \\
\hline & Lokolift & CVD & Active gait & Healthy & GRF & {$[72]$} \\
\hline & Flora & CVD & Active gait & Healthy & Knee and hip angle & {$[73]$} \\
\hline & \multirow{2}{*}{ Ikeuchi's research } & \multirow{2}{*}{ CVD } & Active gait & Healthy & GRF & {$[74]$} \\
\hline & & & Active gait & Healthy & Unloading force & {$[75]$} \\
\hline & BWS system & CVD & Active gait & Healthy & GRF & {$[76]$} \\
\hline & KineAssist & CVD & Active gait & - & & {$[77]$} \\
\hline & & & & - & & {$[63]$} \\
\hline & \multirow{3}{*}{ Where } & \multirow{3}{*}{ CVD } & \multirow{3}{*}{ Active gait } & Healthy & Unloading force & {$[78]$} \\
\hline & & & & Healthy & Unloading force & [79] \\
\hline & & & & Healthy & Unloading force & {$[80]$} \\
\hline & Mouri's research & Other & Active gait & - & GRF & {$[81]$} \\
\hline & \multirow{2}{*}{ Franz's research } & \multirow{2}{*}{ Other } & \multirow{2}{*}{ Active gait } & Healthy & GRF Unloading force & {$[82]$} \\
\hline & & & & Healthy & GRF unloading force & {$[83]$} \\
\hline & LiteGait & Other & Active gait & - & & {$[84]$} \\
\hline & AID-1-M & CVD & Active gait & 一 & & {$[85]$} \\
\hline
\end{tabular}

improved and that this method of rehabilitation was effective in reteaching walking patterns to the CNS [35]. In collaboration with Uhlenbrock, Hesse developed a gait Trainer (Figure 3) with an added mechanism to control leg position, thus reducing the physical effort needed to guide both of the legs and to ensure reproducibility of instructions during rehabilitation. With this machine, the feet of the patient are fixed onto footplates, one of which is fixed to the center of a planet gear on a planetary gear system allowing the footplate to move back and forth. The ratio of stance phase to swing phase is set at $6: 4$ [36]. In order to verify whether this gait Trainer enables similar ambulatory rehabilitation to conventional methods, Hesse et al. compared EMG signals from the legs of a healthy subject and subjects with CVDinduced hemiparesis when walking with the gait Trainer and when walking with therapist assistance, but did not observe any significant difference in either group [37]. In a study by Werner et al. [38] comparing the effects of walking with a gait Trainer and walking with therapist assistance over 6 weeks of rehabilitation on CVD patients, no significant difference was observed between the two methods based on respective FAC scores. 
TABLE 2: Reference about gait rehabilitation device number 2.

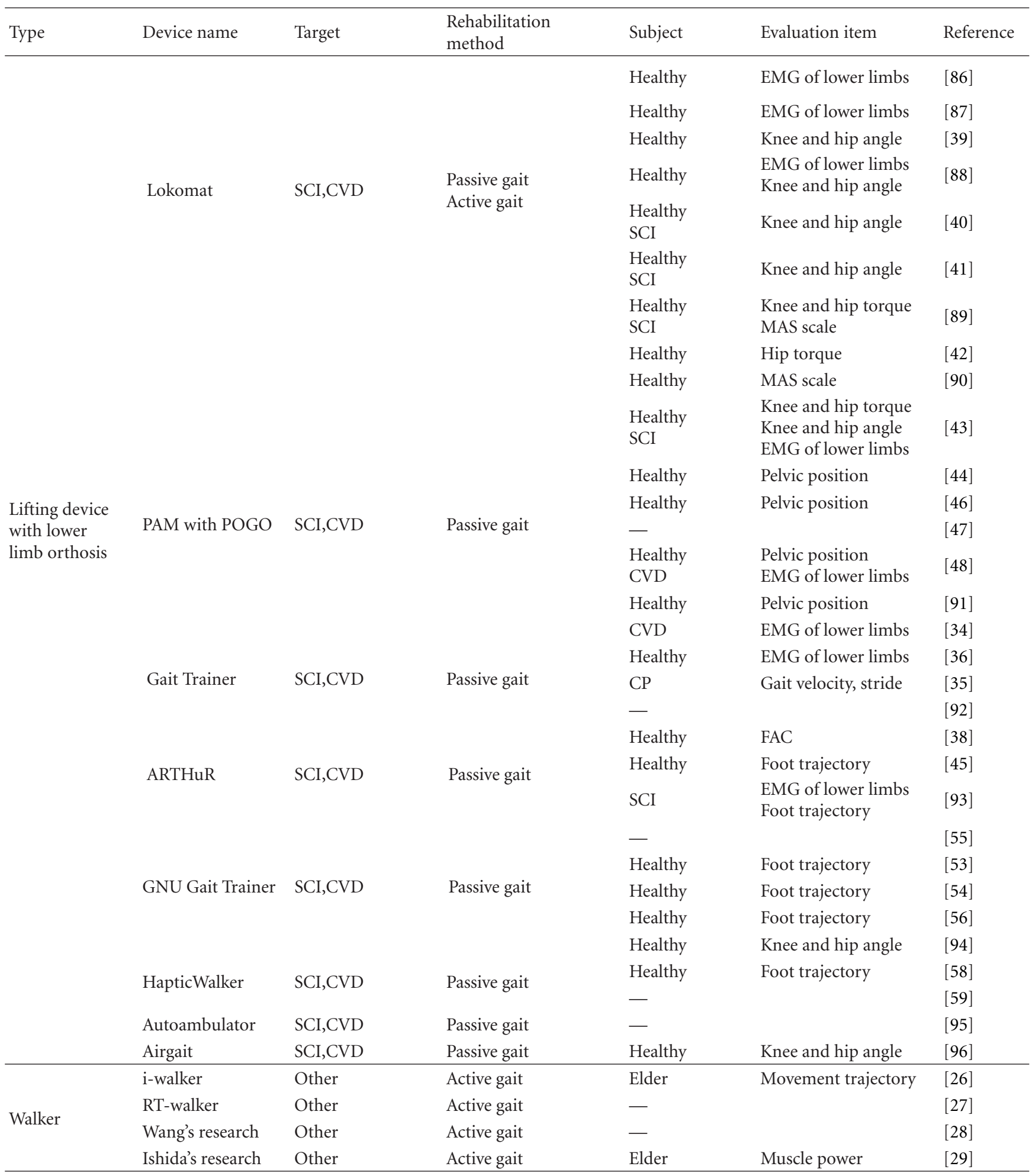

Colombo et al. [39] developed a "driven gait orthosis" (DGO) that guides the hip and knee joints using a twolink robot arm to achieve more normal locomotion of these joints during gait rehabilitation. The DGO comprises a BWS system attached to a treadmill, and motorized devices attached from the hip to the foot. The patient is suspended over the treadmill by a harness attached to the BWS system and is assisted in extending and flexing the knee/hip joints by the attached motors. The angle of each joint is measured by joint potentiometers. The length of the upper and lower leg 


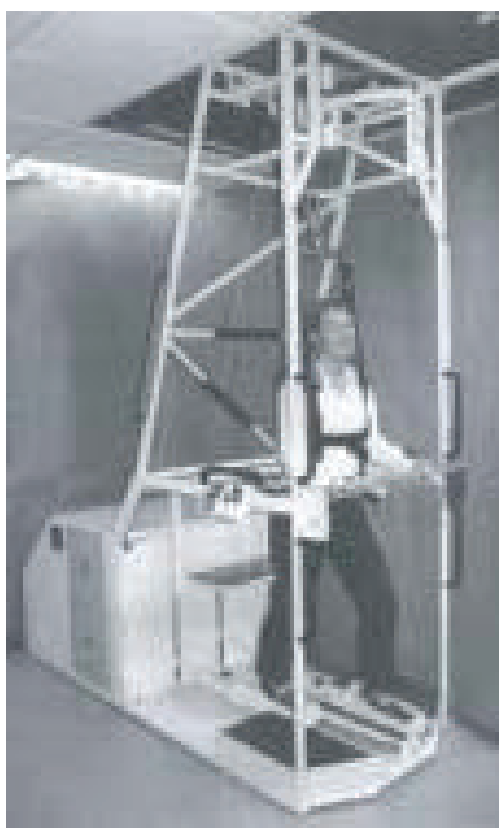

Figure 3: Gait Trainer.

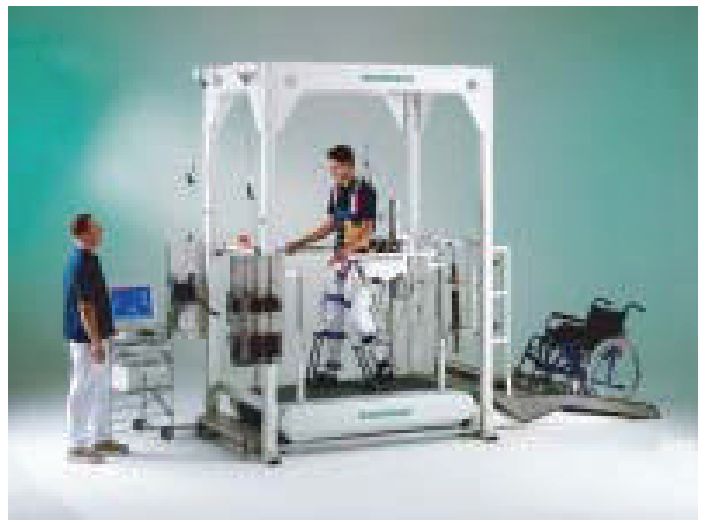

Figure 4: Lokomat.

segments of the orthosis can be adjusted to suit the length of the patient's thigh and lower leg. Joint angle position of the DGO and speed of the treadmill can be controlled in accordance with the gait pattern objectives designated by the therapist. Jezernik et al. [40] subsequently developed the Lokomat (Figure 4) as the successor to the DGO and created an adaptive control algorithm using an impedance controller, adopting the hip and joint angles of healthy subjects as default reference values as a way of controlling the leg motors. However, leg joint angles differ for each individual, so using hip and knee joint angles of another person as reference values forces the human user to compete with the machine and inhibits spontaneous movement of the user. The reference values provided by Lokomat can therefore be adjusted to reduce the estimated interactive torque of the robotic arms and patient's legs. Locomotion experiments were conducted using healthy subjects, with reference values compared against actual measured values, position control

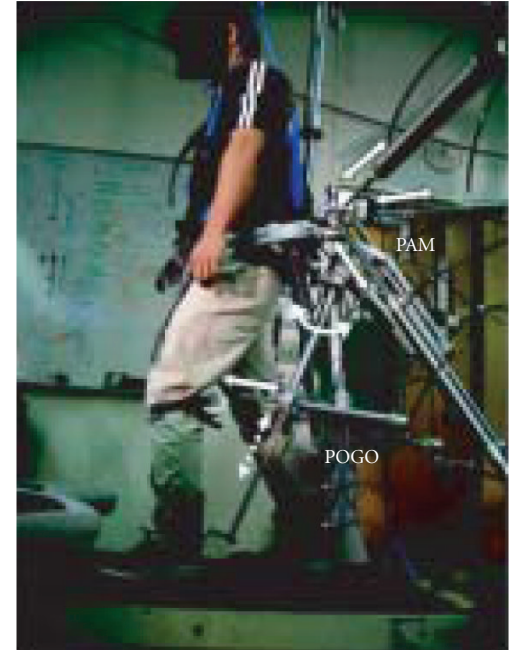

Figure 5: PAM, POGO.

precision was confirmed, and good results were obtained [41]. Interactive torque when using the Lokomat to walk was estimated based on the motor torque produced by automatic movement at each joint using the Lokomat and the torque at each joint produced without using the orthosis. As a result, interactive torque was estimated to increase during the swing phase [42]. Comparison with control based on visual feedback and impedance control indicated the latter method is more effective. A force sensor was attached to the Lokomat and leg maximal muscle strength and leg spasticity evaluation systems were proposed and assessed in patients with neurological disease, and were consequently found to be effective. Four training modes were then integrated with biofeedback and evaluation systems [43]. Ichinose et al. [44] pointed out that the Lokomat and gait Trainer are capable of guiding the legs without restriction, but inhibit the important gait movements of rotating, inclining, and horizontally moving the pelvis and developed the pelvic assist manipulator (PAM) (Figure 5) to address these shortcomings. The PAM comprises a BWS system, a treadmill, and six pneumatic cylinders fixed to a support column positioned behind the patient's pelvis. Force sensors are attached at either end of the pneumatic cylinders, while the ends of the left and right cylinders are attached to the left and right sides of the patient's pelvis. The pneumatic cylinders are used to actuate the pelvis, providing more degrees of freedom (DOF) of pelvic movement and being relatively cheaper per DOF than other actuators. This system can control five DOF, comprising pelvic rotation and obliquity as well as up-down, forward-back, and left-right movements. The PAM controls patient gait by recording the pelvic trajectory of a healthy subject during walking based on the length of the left and right cylinders and then reproducing the trajectory sequence on the patient. Based on an experiment carried out on healthy subjects both with and without the use of the PAM, the precision of pelvic position control with the PAM was found to be good. However, the PAM is unable to guide patient pelvic 


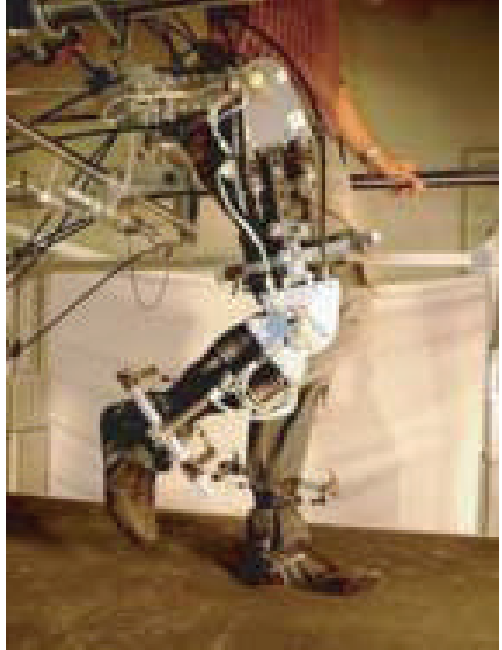

FIGURE 6: LOPES.

movements, so Ichinose et al. developed a new gait training robot known as the Ambulation-assisting Robotic Tool for Human Rehabilitation (ARTHuR) [45], which is capable of guiding pelvic and leg movements. The team also performed pneumatic cylinder modeling and constructed a system that monitors the force generated by the pneumatic cylinders during position control in real time to prevent excessive force from being applied to the patient's body [46]. However, the feed-forward control system that measures and applies the pelvic position of a healthy individual to a patient as reference values sometimes causes considerable force to be applied to the body of the patient, due to differences in individual gait patterns. Such force can result in inhibition of pelvic movement. The researchers therefore came up with a position control method using impedance control to address the need for real-time monitoring of changes in inputs to the patient [47]. Comparing the use and non-use of impedance control in SCI patients revealed that impedance control did not yield a considerable range of pelvic movement. The team also developed the Pneumatically Operated Gait Orthosis (POGO), which guides leg movements using two pneumatic cylinders on each leg, and built a system to integrate this device with the PAM. The first of POGO's pneumatic cylinders is positioned between the pelvis and ankle joint, and the second is set up between the first cylinder and the knee joint [48].

Ekkelenkamp et al. [49] developed the Lower-extremity powered exoSkeleton (LOPES) (Figure 6) to meet the need for ambulatory rehabilitation in various environments so as to acquire practical gait patterns, rather than only in certain external environments such as on a treadmill. LOPES is a gait rehabilitation orthosis with a two-link robot arm applied to the hip and knee joints, with the robot arm attached to a treadmill. A virtual external environment is set up on the treadmill and reaction force applied to the leg is measured based on the angle of leg joints, with the acquired data then used to control the robot arm torque. The LOPES research team validated the responsiveness of torque control and

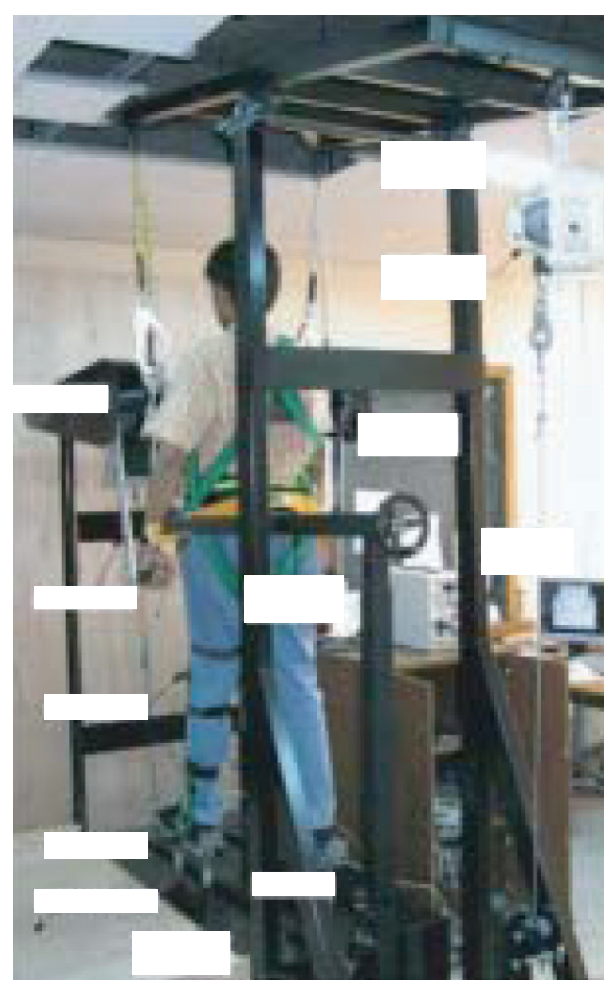

FIgURe 7: GNU Trainer.

confirmed that the reaction force can be communicated to the subject. There is a risk of considerable force being applied to the patient in simple position control mode, so the team developed an impedance controller using the leg joint angles of a healthy subject during gait as reference values. However, comparison of gait patterns of a healthy subject in terms of leg EMG signals and leg joint angles with and without the use of LOPES did not reveal any significant differences [50]. Comparison of leg joint angles in healthy subjects in multiple virtual external environments revealed that angles varied according to the environment [51]. Gait patterns of healthy subjects were compared in terms of leg EMG signals and joint angles using a treadmill and the LOPES device with the aim of reducing impedance parameters and confirming the impact of the device. As a result, use of the LOPES device was found to increase pelvic inclination and alter leg muscular activity, and these outcomes were attributed to the inertia of the device itself [52]. The GNU Trainer (Figure 7) is a gait rehabilitation orthosis utilizing a BWS system without a treadmill $[53,54]$. Gait rehabilitation can be effective when conducted in various environments, so we have developed a gait rehabilitation system for use in virtual external environments. The BWS mechanism comprises wires attached to both shoulders and suspended by a winch via springs. A motorized single-axis pendulum is mounted on the shoulders of the patient to assist with swinging motions of the arms. Footplates control the foot angle and position, while a bilateral base portion is moved backwards and forward by a single motor via a belt. The footplates attached to the base are controlled by two cylinders and one 


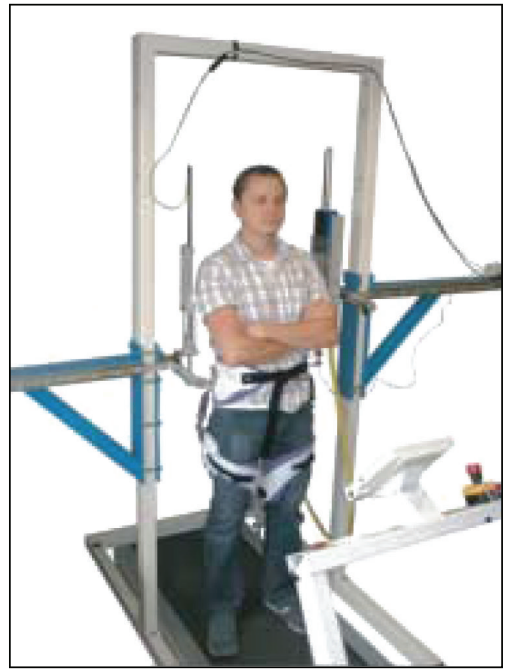

FIGURE 8: RGR Trainer.

linear slider, with the cylinders mounted to the heel and toe portions to control heel and toe heights, and the linear slider is attached to the plantar portion to control forward and backward movements of the footplates. A device for fixing pelvic position of the patient is secured to the BWS unit and prohibits pelvic movement during gait rehabilitation.

A liquid crystal display (LCD) is set up in front of the patient's line of sight and displays images of virtual external environments during rehabilitation. A basic gait pattern is designated based on the gait data of a healthy subject and the walking speed; step size and maximum plantar angle are set while the arm link cycle; base cycle and cylinder orbit are determined before commencing rehabilitation. A target value is then designated for the virtual external environment and the patient is induced to walk. Following testing on healthy subjects to confirm the setting precision of the walking route according to the virtual external environment, the ability of the orthosis to induce walking was demonstrated. We proposed a footplate mechanism with four DOF based on the notion that a more realistic feedback system could be constructed by controlling not only ankle joint angle and foot position, but also inward and outward ankle joint rotations and metatarsophalangeal (MTP) articulations [55]. Conventional methods have controlled the base portion symmetrically using a single motor, but the gait of CVD patients is asymmetrical, so we proposed a mechanism with independent left and right bases and conducted a locomotion experiment to validate this method [56]. Pietrusinski et al. [57] developed the Robotic Gait Rehabilitation (RGR) Trainer (Figure 8) to guide the pelvic movements of CVD patients during gait rehabilitation. Although pelvic motions of CVD patients are already restricted during walking, the Lokomat orthosis further limits movement of the pelvis. The PAM enables passive mechanical movement of the pelvis, but spontaneous pelvic movement by the patient has proven to be difficult. The RGR Trainer was therefore developed to provide assistance to the patient without inhibiting spontaneous pelvic movements. The system comprises left and right support portions attached to a treadmill. The support

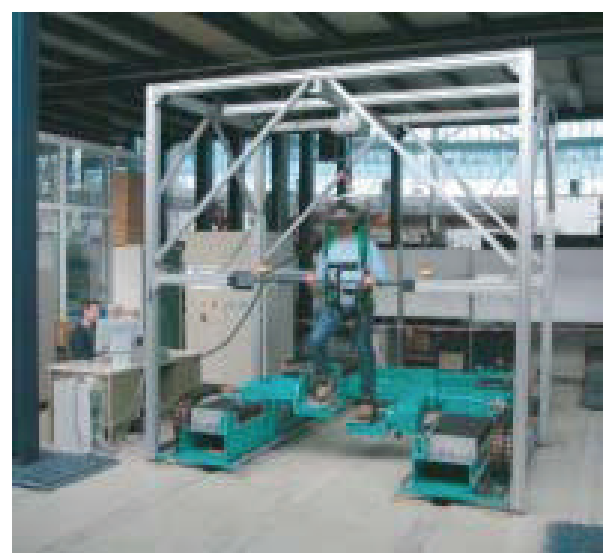

FIGURE 9: HapticWalker.

portions comprise a load cell, encoder, and cylinder. Pelvic positions of a healthy subject during a gait cycle are used as reference values and force is controlled relative to position error in the vertical direction by feedback of load cell values. Maciej et al. confirmed the frequency response of this system and the fact that the RGR Trainer does not inhibit pelvic movements. After measuring the gait patterns of a healthy subject with and without use of the RGR Trainer, the inventors also established that no significant differences exist in respective pelvic position data.

Schmidt et al. [58, 59] developed the HapticWalker (Figure 9) with the aim of providing tactile feedback to patients during gait rehabilitation. Providing feedback on the force exerted on the foot is crucial in gait rehabilitation of CVD patients. Conducting rehabilitation in various environments is also important to acquire a practical gait pattern. Schmidt et al. therefore developed a gait rehabilitation system for use in simulated external environments. The HapticWalker comprises three DOF footplates attached to a BWS system. The footplates control ankle joint flexion and extension, as well as sagittal and vertical foot positions. The patient walks in the simulated external environment wearing a head-mounted display and force exerted on the foot is controlled based on feedback from six DOF force sensors attached to the footplates. Agrawal and Fattah [60] proposed a passive gait rehabilitation system without the use of motive energy, based on the assumption that mechanical gait rehabilitation systems that use motive energy to automatically move the legs may actually inhibit spontaneous movements by the patient. The proposed system targets patients with CVD, Guillain-Barre syndrome, multiple sclerosis, and severe muscle weakness. It comprises a device attached to the pelvic and knee joints and a brace for securing this device. The device is a two-link arm employing a parallelogram linkage mechanism at the knee joint portion, while springs from the upper lumbar and lower thigh regions assist hip joint flexion and extension, in addition to knee joint flexion. Agrawal et al. demonstrated the efficacy of the system after conducting kinematic analysis and estimating assisted hip/knee joint torque. To demonstrate the efficacy of the prototype, the inventors measured the gait patterns of a healthy subject in terms of EMG signals and knee 


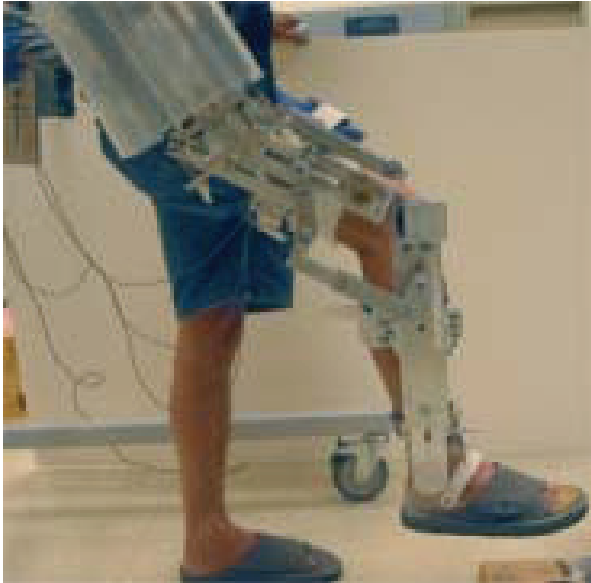

FIgURE 10: GBO.

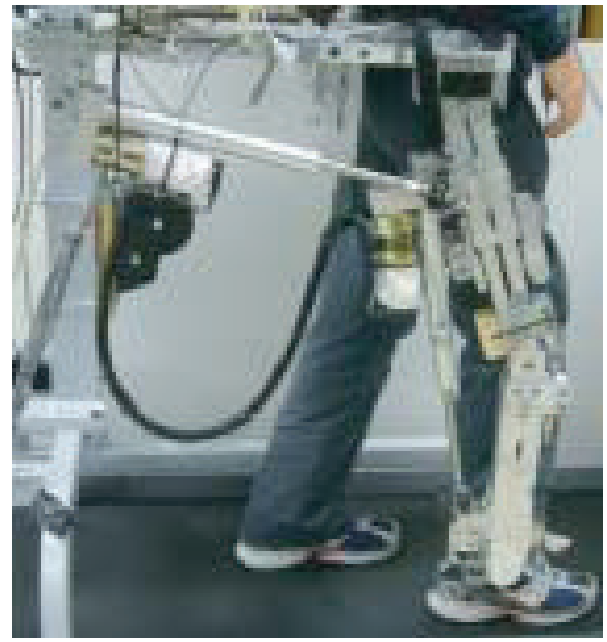

Figure 11: ALEX. joint angles both with and without use of the device, and subsequently found that hip/knee joint movements were similar, but that muscle activity was reduced when using the prototype. Furthermore, measurement of knee and hip joint angles during gait of stroke patients with and without the prototype device revealed that using the device did not yield considerable ranges of knee/hip joint movement.

Based on those research findings, Agrawal et al. developed a gravity-balancing orthosis (GBO) (Figure 10). Banala et al. measured the changes in hip/knee joint angle torque during gait after altering the rate of leg motion assistance provided by the orthosis using a two-link model [62]. Choon-Young and Ju-Jang [63] developed a mobile gait rehabilitation orthosis with a BWS unit. The orthosis is capable of self-propulsion using two motorized drive wheels at the base portion. The motorized BWS unit is secured to the base. Lee et al. developed an orthosis movement algorithm and designated a reference trajectory, then performed a simulation. Constructing a BWS algorithm and modeling the human body as a spring-mass-damper system, the team also designated a reference BWS force and performed a BWS simulation [78]. Coming up with an optimal controller setting to control the BWS mechanism has proven difficulty in the past, as each subject is different. To overcome this issue, Lee et al. created a learning controller utilizing neural networks. The team successfully performed a BWS experiment on a subject while measuring the BWS force [79]. The BWS mechanism operates at a constant force using a simple control system, allowing the team to develop a mechanism linking a pneumatic cylinder in parallel with a motor. After designating reference BWS values and performing a BWS simulation, the team obtained good results [80]. Banala et al. [65] developed the Active Leg EXoskeleton (ALEX) (Figure 11) using a treadmill and motorized leg orthosis. The body of the patient is supported by a thigh device while linear actuators and load cells are attached to the hip and knee joints. The patient walks while looking at the reference foot trajectory appearing on the display placed in front of them. The display also shows the actual foot trajectory of the patient in real time. The orthosis is controlled by linear actuator force commands to the hip and knee joints, with commands generated by calculating the deviation in actual foot joint position and reference position based on feedback of hip and knee joint angles and gait speed. A healthy subject walked on the ALEX orthosis for $1 \mathrm{~h}$ to confirm the learning effects on patients. As a result, Banala et al. confirmed the efficacy of the system based on the error between the reference trajectory before and after the experiment. The efficacy of the ALEX was also confirmed on a stroke patient who underwent 15-day gait rehabilitation on the orthosis based on increases in gait speed and declines in reference trajectory error observed after the experiment [66]. Yoshiyuki et al. [96] developed the "airgait" gait rehabilitation orthosis using the motive power of McKibben pneumatic artificial muscles (PAMs). The actuators are PAMs, and so have the benefits of being lightweight and capable of generating substantial power. The airgate itself comprises a motorized orthosis, counterweight BWS unit, and treadmill. The motorized orthosis is secured to the treadmill by a parallel linkage with gas spring. The PAMs are arranged as antagonistic biarticular and monoarticular muscles modeled on the human musculoskeletal system. After setting the reference knee and hip joint angles and reference pressure levels for PAMs, pressure commands are issued to each of the PAMs based on feedback on the current values of knee and hip joint angles and respective pressure levels of PAMs. Shibata et al. tested the accuracy of the airgait's positional control by conducting a gait session on a healthy subject and comparing reference and actual measured values. The AutoAmbulator [95] is a gait rehabilitation orthosis with a BWS system developed by HealthSouth. This orthosis comprises a BWS system, treadmill, and hip and knee joint devices that are secured to the treadmill. The attached devices guide the legs of the patient according to the reference gait trajectory and speed set by the therapist. Tokioka and Watanabe [73] developed a weight-bearing BWS orthosis named Flora that lifts the user with a crane attached to a steel ceiling with a permanent magnet. The BWS portion employs a constant force spring and motor. The gait mode in Flora is activated by a therapist using the switch controller. 
In an experiment using the Flora orthosis on a healthy subject, Tokioka et al. confirmed that raising the BWS lift force of the device increased gait cycle and reduced step size. Frey et al. [72] developed a BWS system called Lokolift using a spring and a motor. Lokolift comprises a lifting wire connected to a harness worn by the patient, a motor that controls the length of the wire, and a motor that controls the wire tension via a spring. Frey et al. tested the precision of the lifting force control from Lokolift by lifting a healthy subject during gait and obtained good results. Gazzani et al. [70] developed the walking assistance and rehabilitation device (WARD) BWS system using a pneumatic cylinder. After conducting a gait experiment on healthy subjects while varying the lifting force in order to demonstrate the effects of lifting force on gait action, Gazzani et al. found that increasing the lifting force reduced gait speed and that lifting the subject at a force equivalent to $70-80 \%$ of body weight makes walking difficult. Surdilovic et al. [71] developed a BWS system called STRING-MAN, which attaches multiple wires to the anterior and posterior trunk and controls the zero moment point (ZMP) of the patient. The aim of using this device is to reteach balance during gait by controlling the ZMP. Surdilovic et al. developed an algorithm to control the ZMP via a parallel wire mechanism and performed ZMP control simulation using a kinesiological model, then investigated the number of wires needed and built a prototype. Peshkin et al. [77] developed the KineAssist robotic device for gait and balance training. KineAssist comprises a mechanism to support the pelvis of the patient and a base to secure the mechanism and perform actuation. This device is intended for gait and balance rehabilitation in patients with CVD and cerebellar ataxia and is designed to facilitate therapist guidance of the patient's legs without the use of a leg-guiding robotic arm mechanism, based on the notion that orthoses such as the Lokomat that automate leg guidance fail to incorporate the techniques developed by therapists into rehabilitation. KineAssist allows leftright, forward-backwards, and inclined pelvic movements, as well as transverse rotations and movements. Watanabe et al. [76] developed a BWS system to alleviate leg burden during gait rehabilitation. The system comprises a pelvic support device attached to a treadmill. The device features a load cell to measure weight-bearing load, an encoder to measure transverse pelvic rotation angle, and a motorized mechanism that moves up and down. The system allows leftright, forward-backwards, and inclined movements as well as transverse rotation of the pelvis. The controller operates as follows. Values from the encoder are used to estimate heel-contact and toe-off and reference lift force values are designated accordingly. Device motor speed commands are then generated based on the error between load cell values and the reference lifting force. Fujie et al. tested the precision of lifting force control for the BWS system by lifting a healthy subject during gait. Lee and Sankai [61] developed a powered exoskeleton known as the Hybrid Assistive Limb (HAL) that drives motors positioned at each of the user's joints based on surface EMG signals. HAL is a wearable exoskeleton with motors attached to the hip and knee joints of the user. Electrodes are attached to the anterior and posterior lower and upper thighs to measure EMG signals. The measured signals are converted into absolute values, hip and knee joint torques are estimated, and the estimates are then used to generate torque commands. HAL is researched as a study device of gait pattern for CNS patients. Ikeuchi et al. [74] developed a gait support device that lifts the subject using a crane moving back and forth along an elliptical rail. They researched how to maintain constant leg burden by adjusting the weight-bearing load based on measurements from a floor reaction force gauge built into the walking surface. In an experiment on healthy subjects, a lift control simulation was performed after determining the transfer function from the BWS system to the floor reaction force gauge. While unrelated to gait rehabilitation, we introduce the MIT-MANUS as the motion teaching system for CVD patients. The MIT-MANUS is a therapeutic robotic arm developed by the Massachusetts Institute of Technology (MIT) to provide motion training to CVD patients. MITMANUS is a task-oriented device operated using a horizontal robotic training arm. The user manipulates this arm to move a cursor towards a target displayed on a screen. The device is equipped with a visual feedback unit and also features motorized passive actuation capability to allow users who lack sufficient autonomic movement to reach the target. Rehabilitation using the MIT-MANUS enhances proximal arm muscle strength with sustained, long-term effects [97, 98].

\section{Summary}

Gait rehabilitation devices designed for patients with CNS disorders use actuators and a treadmill to passively move patients with the aim of reteaching gait patterns to the CNS. While research has been conducted on passive actuator mechanisms targeting the pelvis, hip joints and knee joints, no proposals have been made for mechanisms that incorporate the ankle joints. Furthermore, a number of actuator control methods have been suggested. The first is position and impedance control of reference values obtained from the limb movements of a healthy subject. The second is adaptive control whereby the limb movements of a healthy subject are set as default reference values and subsequently adjusted to reduce competing forces between the patient and actuator. The third is model-based control estimating the necessary force using inverse kinematic modeling based on the patient's joints. These control methods should be determined according to the condition of the patient and the intended type of input stimuli and are targeted at patients with CNS disorders. However, no studies on control methods have yet been aimed at subjects with orthopedic disorders such as bone fracture. Given the state of research at present, there is currently a need for mechanical devices that passively actuate the pelvis and hip, knee and ankle joints. There is also a need for actuator control methods that target specific disorders.

\section{Acknowledgments}

The authors would like to give special thanks to Yoshifumi Yasuda, Professor in Toyohashi University of Technology's, 
Head of Health Science Center, for his guidance and help. Some of our ideas and examples are from Dr. Yasuda.

\section{References}

[1] P. Langhorne, G. Taylor, G. Murray et al., "Early supported discharge services for stroke patients: a meta-analysis of individual patients' data," The Lancet, vol. 365, no. 9458, pp. 501-506, 2005.

[2] P. Langhorne, L. Widen-Holmqvist, G. Taylor et al., "Early supported discharge after stroke," Journal of Rehabilitation Medicine, vol. 39, no. 2, pp. 103-108, 2007.

[3] A. M. Thorsén, L. W. Holmqvist, J. De Pedro-Cuesta, and L. Von Koch, "A randomized controlled trial of early supported discharge and continued rehabilitation at home after stroke: five-year follow-up of patient outcome," Stroke, vol. 36, no. 2, pp. 297-302, 2005.

[4] Y. F. Kuo, G. V. Ostir, C. V. Granger, and K. J. Ottenbacher, "Examination of follow-up therapy in patients with stroke," American Journal of Physical Medicine and Rehabilitation, vol. 85, no. 3, pp. 192-200, 2006.

[5] T. Graham Brown, "The intrinsic factors in the act of progression in the mammal," Proceedings of the Royal Society $B$, vol. 84, pp. 308-319, 1911.

[6] S. Grillner, "Control of locomotion in bipeds, tetrapods, and fish," Proceedings of the Royal Society B, vol. 84, pp. 308-319, 1911.

[7] S. Grillner, T. Deliagina, O. Ekeberg et al., "Neural networks that co-ordinate locomotion and body orientation in lamprey," Trends in Neurosciences, vol. 18, no. 6, pp. 270-279, 1995.

[8] A. M. Laursen, P. Dyhre-Poulsen, A. Djorup, and H. Jahnsen, "Programmed pattern of muscular activity in monkeys landing from a leap," Acta Physiologica Scandinavica, vol. 102, pp. 492-494, 1978.

[9] B. Bussel, A. Roby-Brami, P. Azouvi, A. Biraben, A. Yakovleff, and J. P. Held, "Myoclonus in a patient with spinal cord transection. Possible involvement of the spinal stepping generator," Brain, vol. 111, no. 5, pp. 1235-1245, 1988.

[10] B. Bussel, A. Roby-Brami, O. R. Néris, and A. Yakovleff, "Evidence for a spinal stepping generator in man. Electrophysiological study," Acta Neurobiologiae Experimentalis, vol. 56, no. 1 , pp. 465-468, 1996.

[11] B. Bussel, A. Roby-Brami, A. Yakovleff, and N. Bennis, "Late flexion reflex in parapletic patients. Evidence for a spinal stepping generator," Brain Research Bulletin, vol. 22, no. 4, pp. 53-56, 1989.

[12] B. Calancie, B. Needham-Shropshire, P. Jacobs, K. Willer, G. Zych, and B. A. Green, "Involuntary stepping after chronic spinal cord injury: evidence for a central rhythm generator for locomotion in man," Brain, vol. 117, no. 5, pp. 1143-1159, 1994.

[13] V. Dietz, "Human neuronal control of automatic functional movements: interaction between central programs and afferent input," Physiological Reviews, vol. 72, no. 1, pp. 33-69, 1992.

[14] D. P. Ferris, K. E. Gordon, J. A. Beres-Jones, and S. J. Harkema, "Muscle activation during unilateral stepping occurs in the nonstepping limb of humans with clinically complete spinal cord injury," Spinal Cord, vol. 42, no. 1, pp. 14-23, 2004.

[15] H. Barbeau and S. Rossignol, "Recovery of locomotion after chronic spinalization in the adult cat," Brain Research, vol. 412, no. 1, pp. 84-95, 1987.
[16] R. D. De Leon, J. A. Hodgson, R. R. Roy, and V. R. Edgerton, "Locomotor capacity attributable to step training versus spontaneous recovery after spinalization in adult cats," Journal of Neurophysiology, vol. 79, no. 3, pp. 1329-1340, 1998.

[17] A. Jaillard, C. D. Martin, K. Garambois, J. François Lebas, and M. Hommel, "Vicarious function within the human primary motor cortex? A longitudinal fMRI stroke study," Brain, vol. 128, no. 5, pp. 1122-1138, 2005.

[18] R. J. Nudo, B. M. Wise, F. SiFuentes, and G. W. Milliken, "Neural substrates for the effects of rehabilitative training on motor recovery after ischemic infarct," Science, vol. 272, no. 5269, pp. 1791-1794, 1996.

[19] R. J. Nudo, G. W. Milliken, W. M. Jenkins, and M. M. Merzenich, "Use-dependent alterations of movement representations in primary motor cortex of adult squirrel monkeys," Journal of Neuroscience, vol. 16, no. 2, pp. 785-807, 1996.

[20] M. Visintin, H. Barbeau, N. Korner-Bitensky, and N. E. Mayo, "A new approach to retrain gait in stroke patients through body weight support and treadmill stimulation," Stroke, vol. 29, no. 6, pp. 1122-1128, 1998.

[21] V. Dietz, "Body weight supported gait training: from laboratory to clinical setting," Brain Research Bulletin, vol. 78, no. 1, pp. 1-4, 2009.

[22] J. B. Dingwell, J. S. Ulbrecht, J. Boch, M. B. Becker, J. T. O'Gorman, and P. R. Cavanagh, "Neuropathic gait shows only trends towards increased variability of sagittal plane kinematics during treadmill locomotion," Gait and Posture, vol. 10, no. 1, pp. 21-29, 1999.

[23] M. D. Lewek, "The influence of body weight support on ankle mechanics during treadmill walking," Journal of Biomechanics, vol. 44, no. 1, pp. 128-133, 2011.

[24] M. K. Aaslund and R. Moe-Nilssen, "Treadmill walking with body weight support. Effect of treadmill, harness and body weight support systems," Gait and Posture, vol. 28, no. 2, pp. 303-308, 2008.

[25] V. Dietz, R. Müller, and G. Colombo, "Locomotor activity in spinal man: significance of afferent input from joint and load receptors," Brain, vol. 125, no. 12, pp. 2626-2634, 2002.

[26] K. Takehito and T. Sosuke, "Walking direction control of the i-walker: the intelligently controllable walker aimed to assist gaits of the elderly people," in Proceedings of the JSME Symposium on Welfare Engineering, pp. 522-525, 2010.

[27] A. Hara, Y. Hirata, and K. Kosuge, "Environment-adaptive motion control for passive type intelligent walking support system "RT walker"," in Proceedings of the International Conference on Intelligent Robots and Systems (IROS '04), vol. 4, pp. 3871-3876, The Japan Society of Mechanical Engineers, September-October 2004.

[28] S. Wang, K. Ishida, and M. Fujie, "A new walk training machine for the severe patients," in Proceedings of the 27th Annual Conference of the Robotics Society of Japan, pp. 34-35, The Japan Society of Mechanical Engineers, 2009.

[29] K. Ishida, S. Wang, and T. Kishi, "Development of all-way mobile walker," in Proceedings of the JSME Symposium on Welfare Engineering, pp. 36-38, 2009.

[30] M. Goldfarb and W. K. Durfee, "Design of a controlledbrake orthosis for FES-aided gait," IEEE Transactions on Rehabilitation Engineering, vol. 4, no. 1, pp. 13-24, 1996.

[31] R. Williamson and B. J. Andrews, "Gait event detection for FES using accelerometers and supervised machine learning," IEEE Transactions on Rehabilitation Engineering, vol. 8, no. 3, pp. 312-319, 2000.

[32] M. Goldfarb, K. Korkowski, B. Harrold, and W. Durfee, "Preliminary evaluation of a controlled-brake orthosis for 
FES-aided gait," IEEE Transactions on Neural Systems and Rehabilitation Engineering, vol. 11, no. 3, pp. 241-248, 2003.

[33] M. M. Skelly and H. J. Chizeck, "Real-time gait event detection for paraplegic FES walking," IEEE Transactions on Neural Systems and Rehabilitation Engineering, vol. 9, no. 1, pp. 5968, 2001.

[34] S. Hesse, M. Konrad, and D. Uhlenbrock, "Treadmill walking with partial body weight support versus floor walking in hemiparetic subjects," Archives of Physical Medicine and Rehabilitation, vol. 80, no. 4, pp. 421-427, 1999.

[35] M. R. Schindl, C. Forstner, H. Kern, and S. Hesse, "Treadmill training with partial body weight support in nonambulatory patients with cerebral palsy," Archives of Physical Medicine and Rehabilitation, vol. 81, no. 3, pp. 301-306, 2000.

[36] S. Hesse and D. Uhlenbrock, "A mechanized gait trainer for restoration of gait," Journal of Rehabilitation Research and Development, vol. 37, no. 6, pp. 701-708, 2000.

[37] S. Hesse, "Treadmill training with partial body weight support after stroke: a review," NeuroRehabilitation, vol. 23, no. 1, pp. 55-65, 2008.

[38] C. Werner, S. Von Frankenberg, T. Treig, M. Konrad, and S. Hesse, "Treadmill training with partial body weight support and an electromechanical gait trainer for restoration of gait in subacute stroke patients: a randomized crossover study," Stroke, vol. 33, no. 12, pp. 2895-2901, 2002.

[39] G. Colombo, M. Joerg, R. Schreier, and V. Dietz, "Treadmill training of paraplegic patients using a robotic orthosis," Journal of Rehabilitation Research and Development, vol. 37, no. 6, pp. 693-700, 2000.

[40] S. Jezernik, G. Colombo, and M. Morari, "Automatic gaitpattern adaptation algorithms for rehabilitation with a 4DOF robotic orthosis," IEEE Transactions on Robotics and Automation, vol. 20, no. 3, pp. 574-582, 2004.

[41] R. Riener, L. Lünenburger, S. Jezernik, M. Anderschitz, G. Colombo, and V. Dietz, "Patient-cooperative strategies for robot-aided treadmill training: first experimental results," IEEE Transactions on Neural Systems and Rehabilitation Engineering, vol. 13, no. 3, pp. 380-394, 2005.

[42] R. Banz, M. Bolliger, and G. Colombo, "Movement analysis with the driven gait orthosis lokomat," Gait and Posture, vol. 24, pp. S215-S216, 2006.

[43] A. Duschau-Wicke, J. Von Zitzewitz, A. Caprez, L. Lünenburger, and R. Riener, "Path control: a method for patientcooperative robot-aided gait rehabilitation," IEEE Transactions on Neural Systems and Rehabilitation Engineering, vol. 18, no. 1, pp. 38-48, 2010.

[44] W. E. Ichinose, D. J. Reinkensmeyer, D. Aoyagi et al., "A robotic device for measuring and controlling pelvic motion during locomotor rehabilitation," in Proceedings of the 25th Annual International Conference of the IEEE Engineering in Medicine and Biology Society, vol. 2, pp. 1690-1693, September 2003.

[45] J. L. Emken, J. H. Wynne, S. J. Harkema, and D. J. Reinkensmeyer, "A robotic device for manipulating human stepping," IEEE Transactions on Robotics, vol. 22, no. 1, pp. 185-189, 2006.

[46] D. Aoyagi, W. Ichinose, D. J. Reinkensmeyer, and J. E. Bobrow, "Human step rehabilitation using a robot attached to the pelvis," in Proceedings of the International Mechanical Engineering Congress and Exposition (IMECE '04), pp. 443449, Anaheim, Calif, USA, November 2004.

[47] D. J. Reinkensmeyer, D. Aoyagi, J. L. Emken et al., "Tools for understanding and optimizing robotic gait training," Journal of Rehabilitation Research and Development, vol. 43, no. 5, pp. 657-670, 2006.
[48] D. Aoyagi, W. E. Ichinose, S. J. Harkema, D. J. Reinkensmeyer, and J. E. Bobrow, "A robot and control algorithm that can synchronously assist in naturalistic motion during body-weightsupported gait training following neurologic injury," IEEE Transactions on Neural Systems and Rehabilitation Engineering, vol. 15, no. 3, pp. 387-400, 2007.

[49] R. Ekkelenkamp, J. Veneman, and H. Van Der Kooij, “Lopes: selective control of gait functions during the gait rehabilitation of CVA patients," in Proceedings of the 9th International Conference on Rehabilitation Robotics (ICORR '05), pp. 361364, July 2005.

[50] E. H. F. Van Asseldonk, R. Ekkelenkamp, J. F. Veneman, F. C. T. Van Der Helm, and H. Van Der Kooij, "Selective control of a subtask of walking in a robotic gait trainer(LOPES)," in 2007 IEEE 10th International Conference on Rehabilitation Robotics (ICORR '07), pp. 841-848, June 2007.

[51] J. F. Veneman, R. Kruidhof, E. E. G. Hekman, R. Ekkelenkamp, E. H. F. Van Asseldonk, and H. Van Der Kooij, "Design and evaluation of the LOPES exoskeleton robot for interactive gait rehabilitation," IEEE Transactions on Neural Systems and Rehabilitation Engineering, vol. 15, no. 3, pp. 379-386, 2007.

[52] E. H. F. Van Asseldonk, J. F. Veneman, R. Ekkelenkamp, J. H. Buurke, F. C. T. Van Der Helm, and H. Van Der Kooij, "The effects on kinematics and muscle activity of walking in a robotic gait trainer during zero-force control," IEEE Transactions on Neural Systems and Rehabilitation Engineering, vol. 16, no. 4, pp. 360-370, 2008.

[53] B. Novandy, J. Yoon, and Y. Christiand, "A VR navigation of a 6-DOF gait rehabilitation robot with upper and lower limbs connections," in Proceedings of the 8th IEEE-RAS International Conference on Humanoid Robots, pp. 592-597, December 2008.

[54] Y. Jungwon, B. Novandy, C. H. Yoon, and K. J. Park, "A 6DOF gait rehabilitation robot with upper and lower limb connections that allows walking velocity updates on various terrains," IEEE/ASME Transactions on Mechatronics, vol. 15, no. 2, Article ID 5424007, pp. 201-215, 2010.

[55] Y. Jungwon and R. Jeha, "A novel reconfigurable ankle/foot rehabilitation robot," in Proceedings of the IEEE International Conference on Robotics and Automation (ICRA '05), pp. 22902295, April 2005.

[56] Y. Jungwon, R. Jeha, P. Jangwoo, and B. Novandy, "Walking analysis of a dual-track treadmill using a foot-platform locomotion interface," in Proceedings of the International Conference on Rehabilitation Robotics (ICORR '09), pp. 851-856, June 2009.

[57] M. Pietrusinski, I. Cajigas, M. Goldsmith, P. Bonato, and C. Mavroidis, "Robotically generated force fields for stroke patient pelvic obliquity gait rehabilitation," in Proceedings of the International Conference on Robotics and Automation (ICRA '10), pp. 569-575, May 2010.

[58] H. Schmidt, D. Sorowka, S. Hesse, and R. Bernhardt, "Design of a robotic walking simulator for neurological rehabilitation," in Proceedings of the IEEE/RSJ International Conference on Intelligent Robots and Systems, vol. 2, pp. 1487-1492, October 2002.

[59] S. Hesse, R. Bernhardt, and J. Kruger, "Hapticwalker-a novel haptic device for walking simulation," ACM Transactions on Applied Perception, vol. 2, no. 2, pp. 166-180, 2005.

[60] S. K. Agrawal and A. Fattah, "Theory and design of an orthotic device for full or partial gravity-balancing of a human leg during motion," IEEE Transactions on Neural Systems and Rehabilitation Engineering, vol. 12, no. 2, pp. 157-165, 2004. 
[61] S. Lee and Y. Sankai, "Power assist control for walking aid with HAL-3 based on EMG and impedance adjustment around knee joint," in Proceedings of the International Conference on Intelligent Robots and Systems, pp. 1499-1504, October 2002.

[62] S. K. Banala, S. K. Agrawal, A. Fattah et al., "Gravitybalancing leg orthosis and its performance evaluation," IEEE Transactions on Robotics, vol. 22, no. 6, pp. 1228-1239, 2006.

[63] L. Choon-Young and L. Ju-Jang, "Walking-support robot system for walking rehabilitation: design and control," Artificial Life and Robotics, vol. 4, no. 4, pp. 206-211, 2000.

[64] S. K. Agrawal, S. K. Banala, A. Fattah et al., "Assessment of motion of a swing leg and gait rehabilitation with a gravity balancing exoskeleton," IEEE Transactions on Neural Systems and Rehabilitation Engineering, vol. 15, no. 3, pp. 410-420, 2007.

[65] S. K. Banala, S. K. Agrawal, and J. P. Scholz, "Active Leg Exoskeleton (ALEX) for gait rehabilitation of motor-impaired patients," in Proceedings of the 10th International Conference on Rehabilitation Robotics (ICORR '07), pp. 401-407, June 2007.

[66] S. K. Banala, S. H. Kim, S. K. Agrawal, and J. P. Scholz, "Robot assisted gait training with active leg exoskeleton (ALEX)," IEEE Transactions on Neural Systems and Rehabilitation Engineering, vol. 17, no. 1, pp. 2-8, 2009.

[67] K. Maeda and J. Nango, "Design of walker with assist equipment translating suspected walking motion to rotational motion," in Proceedings of the JSME Annual Meeting, vol. 4, pp. 13-14, The Japan Society of Mechanical Engineers, 2007.

[68] J. Nango and R. Kato, "Static analysis of pedaling walker with assist equipment," in Proceedings of the JSME Annual Meeting, vol. 4, pp. 203-204, The Japan Society of Mechanical Engineers, 2008.

[69] J. Nango and R. Kato, "Design of walker with planar sixbar mechanisn involving prismatic pair," in Proceedings of the JSME Annual Meeting, vol. 4, The Japan Society of Mechanical Engineers, 2009.

[70] F. Gazzani, A. Fadda, M. Torre, and V. Macellari, "Ward: a pneumatic system for body weight relief in gait rehabilitation," IEEE Transactions on Rehabilitation Engineering, vol. 8, no. 4, pp. 506-513, 2000.

[71] D. Surdilovic, J. Zhang, and R. Bernhardt, "String-man: wire-robot technology for safe, flexible and human-friendly gait rehabilitation," in Proceedings of the 10th International Conference on Rehabilitation Robotics (ICORR '07), pp. 446453, June 2007.

[72] M. Frey, G. Colombo, M. Vaglio, R. Bucher, M. Jörg, and R. Riener, "A novel mechatronic body weight support system," IEEE Transactions on Neural Systems and Rehabilitation Engineering, vol. 14, no. 3, pp. 311-321, 2006.

[73] S. Tokioka and H. Watanabe, "Development of walk-supportsystem flora," Kumagai Technical Research Report, vol. 63, pp. 87-92, 2005.

[74] H. Ikeuchi, K. Onishi, K. Imado, H. Miyagawa, and Y. Saito, "Discussion about characteristics of sling system in gait training system," Proceedings of the Symposium on Biological and Physiological Engineering, vol. 21, pp. 25-28, 2006.

[75] H. Ikeuchi, S. Takiyama, I. Mamoru, and Y. Saito, "Discussion of sling control simulation in feedback type gait training system," in Proceedings of the International Conference on Rehabilitation Robotics (ICORR '09), pp. 360-365, June 2009.

[76] T. Watanabe, E. Ohki, Y. Kobayashi, and M. G. Fujie, "Legdependent force control for body weight support by gait cycle estimation from pelvic movement," in Proceedings of the
International Conference on Robotics and Automation (ICRA '10), pp. 2235-2240, May 2010.

[77] M. Peshkin, D. A. Brown, J. J. Santos-Munné et al., "KineAssist: a robotic overground gait and balance training device," in Proceedings of the 9th International Conference on Rehabilitation Robotics (ICORR '05), pp. 241-246, July 2005.

[78] L. Choon-Young, S. Kap-Ho, O. Changmok, and L. Ju-Jang, "A system for gait rehabilitation with body weight support: mobile manipulation approach," International Journal of Human-Friendly Welfare Robotic Systems, vol. 2, pp. 16-21, 2001.

[79] L. Choon-Young, J. Il-Kwon, L. In ho, K. H. Seo, and J. J. Lee, "Development of rehabilitation robot systems for walkingaid," in Proceedings of the IEEE International Conference on Robotics and Automation (ICRA '04), pp. 2468-2473, May 2004.

[80] S. Kap-Ho and L. Ju-Jang, "The development of two mobile gait rehabilitation systems," IEEE Transactions on Neural Systems and Rehabilitation Engineering, vol. 17, no. 2, Article ID 4785182, pp. 156-166, 2009.

[81] K. Mohri, T. Kishi, J. Ueta, and Y. Tsuno, "Omni-directional walking rehabilitation machine with load support mechanism," in Proceedings of the JSME Symposium on Welfare Engineering, pp. 32-33, 2009.

[82] J. R. Franz, P. O. Riley, J. Dicharry, P. E. Allaire, and D. C. Kerrigan, "Gait synchronized force modulation during the stance period of one limb achieved by an active partial body weight support system," Journal of Biomechanics, vol. 41, no. 15, pp. 3116-3120, 2008.

[83] J. R. Franz, M. Glauser, P. O. Riley et al., "Physiological modulation of gait variables by an active partial body weight support system," Journal of Biomechanics, vol. 40, no. 14, pp. 3244-3250, 2007.

[84] http://www.litegait.com/.

[85] http://www.japanem.co.jp.

[86] T. Erni and G. Colombo, "Locomotor training in paraplegic patients: a new approach to assess changes in leg muscle EMG patterns," Neurobiology Papers, vol. 109, pp. 135-139, 1998.

[87] M. Pijnappels, B. M. H. Van Wezel, G. Colombo, V. Dietz, and J. Duysens, "Cortical facilitation of cutaneous reflexes in leg muscles during human gait," Brain Research, vol. 787, no. 1, pp. 149-153, 1998.

[88] S. Jezernik, G. Colombo, T. Keller, H. Frueh, and M. Morari, "Robotic orthosis lokomat: a rehabilitation and research tool," Neuromodulation, vol. 6, no. 2, pp. 108-115, 2003.

[89] L. Lunenburger, G. Colombo, R. Riener, and V. Dietz, "Clinical assessments performed during robotic rehabilitation by the gait training robot lokomat," in Proceedings of the 9th International Conference Rehabilitation Robotics (ICORR '05), pp. 345-348, 2005.

[90] R. Riener, L. Lünenburger, and G. Colombo, "Humancentered robotics applied to gait training and assessment," Journal of Rehabilitation Research and Development, vol. 43, no. 5, pp. 679-694, 2006.

[91] D. Aoyagi, W. E. Ichinose, S. J. Harkema, D. J. Reinkensmeyer, and J. E. Bobrow, "An assistive robotic device that can synchronize to the pelvic motion during human gait training," in Proceedings of the 9th International Conference on Rehabilitation Robotics (ICORR '05), pp. 565-568, July 2005.

[92] S. Hesse, H. Schmidt, C. Werner, and A. Bardeleben, "Upper and lower extremity robotic devices for rehabilitation and for studying motor control," Current Opinion in Neurology, vol. 16, no. 6, pp. 705-710, 2003. 
[93] J. L. Emken, S. J. Harkema, J. A. Beres-Jones, C. K. Ferreira, and D. J. Reinkensmeyer, "Feasibility of manual teach-andreplay and continuous impedance shaping for robotic locomotor training following spinal cord injury," IEEE Transactions on Biomedical Engineering, vol. 55, no. 1, pp. 322-334, 2008.

[94] Y. Jungwon, "Auralius manurung kinematic and kinetic patterns during gait training on gnu gaittrainer rehabilitation robot," in Proceedings of the International Conference on Management of Innovation and Technology (ICMIT '09), pp. 380383, 2009.

[95] http://medgadget.com/.

[96] S. Yoshiyuki, I. Shingo, N. Tatsuya, and Y. Shinichiro, "Development of body weight support gait training system airgait," in Proceedings of the JSME Symposium on Welfare Engineering, pp. 540-543, 2010.

[97] N. Hogan and H. I. Krebs, "Interactive robots for neurorehabilitation," Restorative Neurology and Neuroscience, vol. 22, no. 3-4, pp. 349-358, 2004.

[98] H. I. Krebs, N. Hogan, M. L. Aisen, and B. T. Volpe, "Robotaided neurorehabilitation," IEEE Transactions on Rehabilitation Engineering, vol. 6, no. 1, pp. 75-87, 1998. 

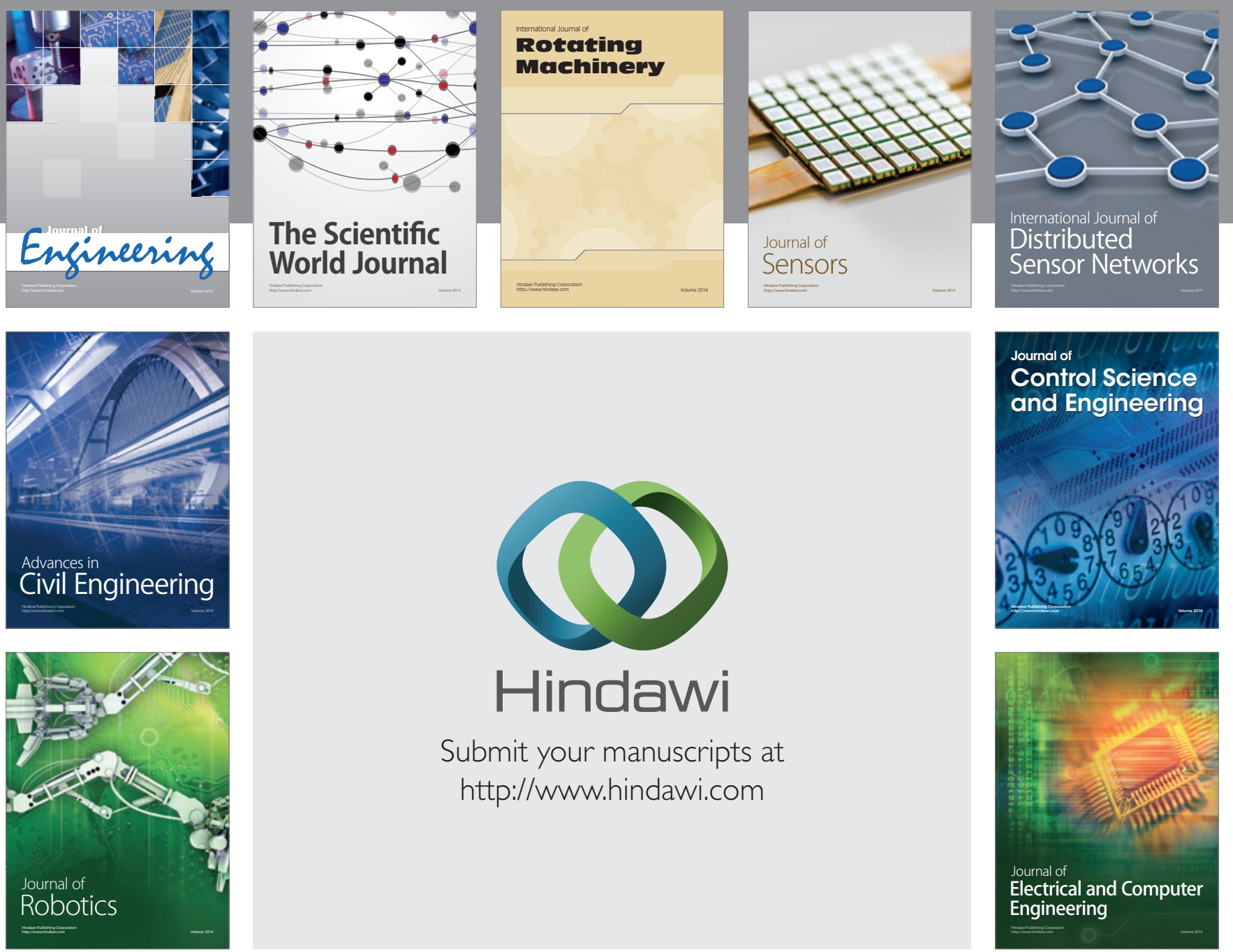

Submit your manuscripts at

http://www.hindawi.com
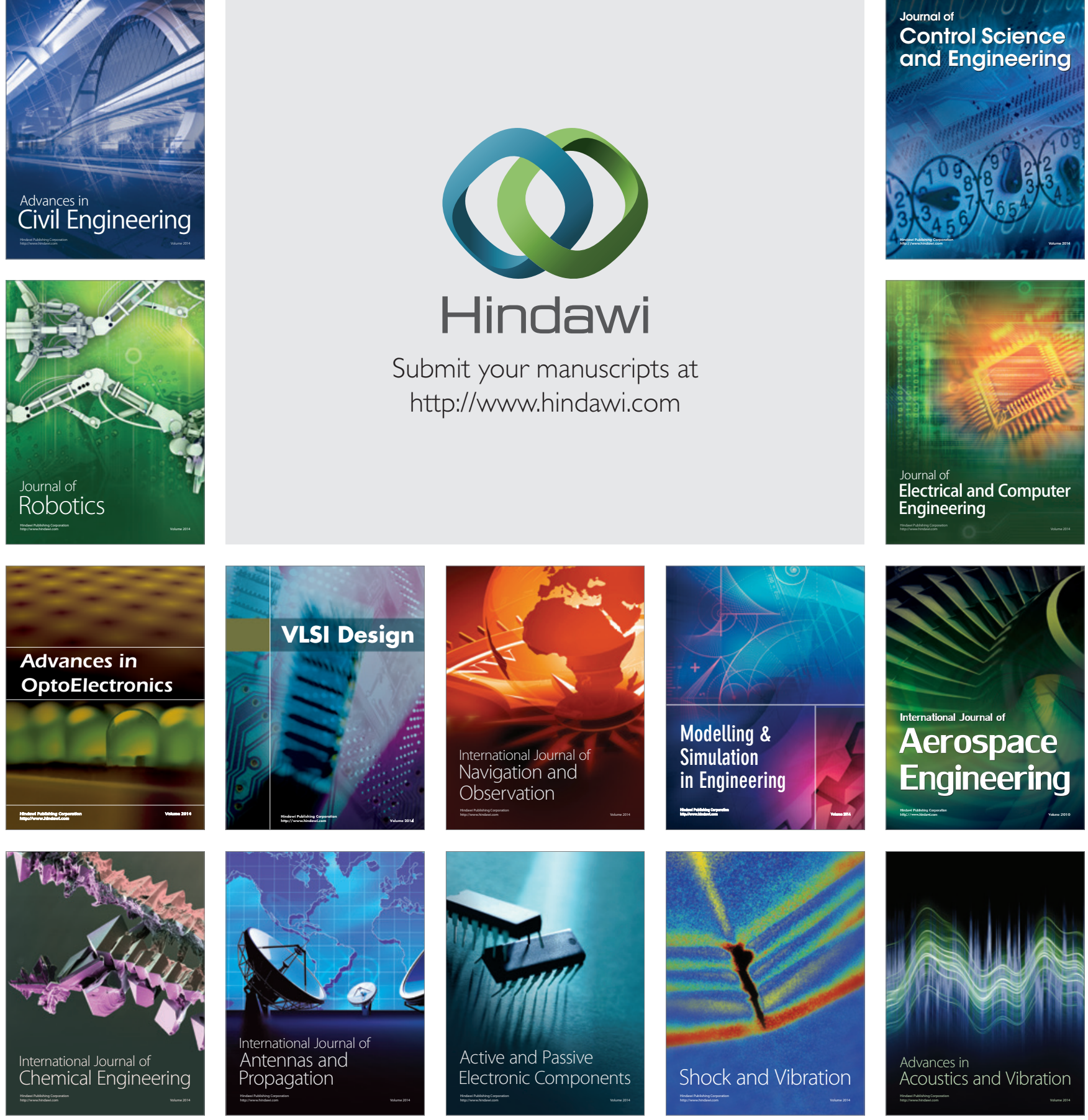